\title{
PENGUTAMAAN BAHASA INDONESIA: SUATU LANGKAH APLIKATIF
}

\author{
Puji Anto \\ Hilda Hilaliyah \\ Taufiq Akbar
}

\author{
Universitas Indraprasta PGRI \\ Jl. Nangka No. 58 C Tanjung Barat, Jagakarsa, Jakarta Selatan \\ puijianto@unindra.ac.id
}

Naskah masuk: 10-01-19, direvisi: 10-02-19, diterima: 10-03-19, dipublikasi: 25-04-19

\begin{abstract}
Abstrak: Terkait bahasa Indonesia, saat ini, belum ada komitmen yang kuat dari para penuturnya untuk menempatkan bahasa Indonesia pada tempat paling utama. Faktanya, perilaku berbahasa oleh penutur bahasa Indonesia cenderung negatif. Hal itu dibuktikan oleh beberapa fakta bahwa eksistensi bahasa Indonesia terancam oleh penggunaan bahasa asing. Terlihat di beberapa instansi pemerintah, swasta, dan tempat-tempat tertentu menggunakan bahasa asing tanpa menyandingkan dengan bahasa Indonesia, apalagi bahasa daerah. Tujuan dari penelitian ini adalah untuk mengejawantahkan peraturan tentang kebahasaan. Jenis penelitian yang digunakan adalah kualitatif deskriptif. Kualitatif deskriptif merupakan penelitian yang melibatkan peneliti sebagai instrumen dalam pengumpulan data. Hasil penelitian ini adalah ada sebelas hal kewajiban penggunaan bahasa Indonesia yang dituangkan dalam poster. Simpulan dari penelitian yang telah dilakukan meliputi fakta dari sikap berbahasa penutur bahasa Indonesia yang cenderung negatif. Oleh sebab itu, diperlukan sebuah langkah inovatif untuk mengubah perilaku atau sikap berbahasa tersebut. Langkah inovatif yang dilakukan, yaitu dengan melakukan membuat poster yang berisi tentang kewajiban penggunaan bahasa Indonesia.
\end{abstract}

Kata kunci: Pengutamaan, bahasa Indonesia, aplikatif.

Abstract: Abstract: the associated language Indonesia, currently, there has not been a strong commitment from their native language to put Indonesia on the foremost place. In fact, the behavior of the Indonesia language speakers by language tends to be negative. It is evidenced by the fact that the existence of some language Indonesia is threatened by the use of a foreign language. Look at several government agencies, the private sector, and certain places using a foreign language without grouping with Indonesia's language, especially the language of the region. The purpose of this research is to embody the rules about linguistics. This type of research is qualitative, descriptive. Descriptive research is qualitative which involves researchers as an instrument in the collection of data. The results of the research there are eleven things Indonesia language obligations are poured into the poster. Summary of the research that has been carried out includes the fact that English-speaking attitude of Indonesia which tends to be negative. Therefore, needed an innovative step to change the behavior or attitude of the language. Innovative measures are undertaken, namely by doing posters containing the obligation of the use of the language of Indonesia.

Keywords: Centrality, Indonesia, applicative language.

\section{PENDAHULUAN}

Bahasa tidak bisa dipisahkan dari dimaksud adalah terkait eksistensi dari penuturnya. Tidak bisa dipisahkan yang bahasa itu sendiri. Keberadaan bahasa, 
baik itu dalam keadaan berkembang maupun terpuruk sangat bergantung dari perilaku berbahasa dari penuturnya. Penutur, semakin baik memperlakukan bahasanya, maka kelestarian bahasa itu akan terjaga. Begitu pun sebaliknya, jika penutur menomorduakan bahasanya dan lebih menomorsatukan bahasa asing, maka dapat dipastikan bahasa asli penutur tersebut terancam pengembangan dan perluasannya. Perubahan bahasa dapat terjadi bukan hanya berupa pengembangan dan perluasan saja, melainkan dapat berupa kemunduran dalam masyarakat.

Tidak dapat dipungkiri pelestarian bahasa sagatlah sulit. Hal itu dikarenakan perkembangan ilmu pengetahuan dunia yang terus berkembang. Banyaknya konsep-konsep baru yang tercetus dari latar belakang bahasa yang berbeda. Hal itu juga memungkinkan penduduk dunia berlomba-lomba menguasai atau menggunakan bahasa asing atau bahasa asli dari konsep tersebut demi mengikuti peradaban iptek. Tidak hanya itu saja, berbagai alasan sosial dan politis menyebabkan banyak orang meninggalkan bahasanya.

Perlu komitmen yang kuat dari penutur bahasa terkait penguasaan bahasa asing tanpa harus mengesampingkan bahasa aslinya. Komitmen tentunya tidak hanya pada ranah tertentu saja, tetapi semua aspek kehidupan berbangsa dan bernegara. Semua komponen harus bersinergi untuk menempatkan bahasa aslinya di tempat yang paling utama. Jika diperlukan, regulasi terkait kebahasaan dilengkapi dengan suatu aturan yang sistematis, contohnya adalah adanya sanksi terkait kesalahan penggunaan bahasa. Penerapan sanksi terhadap para pelanggar kebahasaan akan memberikan efek jera kepada penutur. Sanksi akan menjadi alat kontrol penggunaan sebuah bahasa dari penuturnya. Dengan demikian, pengutamaan sebuah bahasa akan terwujud.

Terkait bahasa Indonesia, saat ini, belum ada komitmen yang kuat dari para penuturnya untuk menempatkan bahasa Indonesia pada tempat paling utama. Faktanya, perilaku berbahasa oleh penutur bahasa Indonesia cenderung negatif. Hal itu dibuktikan oleh beberapa fakta bahwa eksistensi bahasa Indonesia terancam oleh penggunaan bahasa asing. Terlihat di beberapa instansi pemerintah, swasta, dan tempat-tempat tertentu menggunakan bahasa asing tanpa menyandingkan dengan bahasa Indonesia, apalagi bahasa daerah.

Koentjaraningrat dalam (Rizkiansyah \& Rustono, 2017) membagi beberapa sifat negatif masyarakat Indonesia yang tercermin saat berbahasa, yaitu (1) meremehkan mutu, (2) mentalitas menerabas, (3) tuna harga diri, (4) menjauhi disiplin, (5) enggan bertanggung jawab, dan (6) suka latah atau ikut-ikutan. Pendapat di atas terjawab oleh fakta, saat ini masyarakat Indonesia cenderung lebih senang dan merasa lebih modern serta terpelajar jika menggunakan bahasa asing. Hal itulah yang memberikan dampak negatif terhadap pertumbuhan bahasa Indonesia sebagai jati diri bangsa. Bahasa Inggris sebagai bahasa internasional jika tidak disikapi dengan bijak akan memberi dampak buruk pada perkembangan bahasa Indonesia. Kepopuleran bahasa Inggris menjadikan bahasa Indonesia tergeser pada tingkat pemakaiannya. Masyarakat Indonesia lebih sering menggunakan ungkapan "No Smoking" daripada "Dilarang Merokok", "Stop" untuk "setop", "Exit" untuk "keluar", "charger" untuk pengisian daya, "gents" 
untuk "laki-laki", "restroom" untuk "kamar kecil", dan "welcome" untuk "selamat datang".

Penggunaan bahasa Inggris di beberapa tempat umum telah menjadi budaya generasi milenial. Hal itulah yang mengakibatkan lunturnya kewibawaan bahasa Indonesia. Secara perlahan, tetapi pasti, bahasa asing, khususnya Inggris, akan menjadi kebanggaan masyarakat Indonesia. Sikap kurang baik atas bahasa Indonesia telah melanda berbagai kalangan masyarakat di Indonesia, baik kalangan bawah, menengah, dan atas (intelektual). Sikap kurang baik kalangan bawah dan menengah lebih kepada adanya bahasa daerah, sedangkan kalangan atas lebih kepada kurang rasa bangga berbahasa Indonesia dan predikat modern atau terpelajar.

Berikut disampaikan beberapa fakta terkait penggunaan bahasa asing di masyarakat Indonesia.

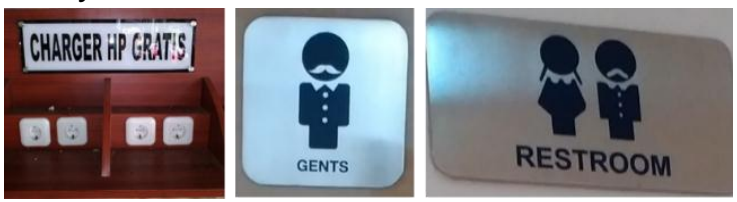

Gambar 1 Fenomena Penggunaan Bahasa Indonesia Sumber: Dokumen Pribadi

Oleh sebab itu, sangat diperlukan langkah-langkah agar bahasa Indonesia dapat menjadi kebanggaan dan jati diri bangsa. Oleh karena itu, mengacu slogan Badan Pengembangan dan Pembinaan Bahasa Kemendikbud atau trigatra bangun bahasa yang terdiri dari:"utamakan bahasa Indonesia, lestarikan bahasa daerah, kuasai bahasa asing", maka perlu adanya gerakan masif untuk menyosialisasikan hal tersebut. Makna trigatra bangun bahasa adalah kenyataan bahwa negara Indonesia mempunyai masyarakat yang multibahasa, maka diperlukan aturan penggunaan ruang berbahasa yang mencakup berbahasa Indonesia, berbahasa daerah, dan berbahasa asing, agar masyarakat dapat terfasilitasi dan proporsinya tepat.

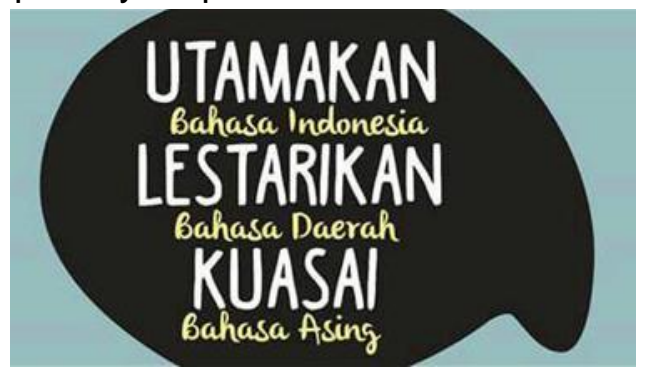

Gambar 2 Trigatra Bangun Bahasa

Sumber: Badan Pengembangan dan Pembinaan Bahasa

Oleh karena itu, penelitian akan merancang sebuah media sosialisasi terkait penggunaan bahasa di Indonesia, focus kepada pengutamaan bahasa Indonesia. Media yang digunakan adalah poster. Nantinya, poster akan dipublikasikan secara digital. Alasan penggunaan media digital atau teknologi informasi dan komunikasi mengarah kepada generasi melenial yang kesehariaanya tidak lepas dari gawai. Tidak menutup kemungkinan media ini juga akan menjangkau seluruh masyarakat Indonesia. Hal itu sesui dengan Siaran Pers No.22/HM/KOMINFO/01/2018 Tanggal 31 Januari 2018 tentang Survei Penggunaan Tik serta Implikasinya terhadap Aspek Sosial Budaya Masyarakat. Adapun sasaran dari survei tersebut antara lain rumah tangga dan individu dengan kategori usia 9-65 tahun sebanyak 9.419 orang. Survei tersebut sudah disebarkan pada 34 provinsi yang meliputi 142 kabupaten/kota dan terdiri dari 604 desa yang mencakup 51,24\% responden di desa rural (perdesaan) dan $48,76 \%$ di desa urban (perkotaan) (Kementerian Komunikasi dan Informatika, 2018). 
hasil survei,

Berdasarkan tersusunlah data yang komprehensif mencakup kepemilikan dan penggunaan perangkat TIK. Selain itu, hasilnya juga menunjukkan implikasi penggunaan perangkat TIK terhadap aspek sosial budaya, serta penggunaan media sosial dan instant messaging di wilayah urban dan luar Indonesia (Kementerian Komunikasi dan Informatika, 2018).

Pada aspek kepemilikan smartphone (Telepon Pintar), responden yang memiliki telepon pintar sebesar 66,3\%. Berdasarkan wilayah dari responden di perkotaan kepemilikan telepon pintar mencapai $83,04 \%$ sementara di perdesaan sebesar 50,39\% (Kementerian Komunikasi dan Informatika, 2018).

Penggunaan perangkat TIK pada aspek sosial budaya antara lain mengungkapkan bahwa mayoritas PNS/TNI/Polri, karyawan swasta dan Non$\mathrm{PNS} /$ honorer menghabiskan pulsa lebih dari Rp 100.000- sebulan. Survei ini juga menggambarkan pengguna Instant Messaging (IM) Whatsapp (WA) cukup dominan, baik di wilayah perdesaan maupun perkotaan yang mencapai $65,10 \%$ dengan responden terbanyak pada kelompok usia 20-29 tahun (Kementerian Komunikasi dan Informatika, 2018).

Tujuan dari penelitian ini adalah untuk mengejawantahkan peraturan tentang kebahasaan yang saat ini sangat diabaikan. Peraturan kebahasaan yang dimaksud adalah penggunaan bahasa Indonesia di semua aspek kehidupan masyarakat dalam lingkup Negara Kesatuan Republik Indonesia.

Manfaat dari penelitian ini adalah sebagai petunjuk praktis bagi masyarakat Indonesi yang berkaitan dengan kebahasaan. Kebahasaan yang dimaksud adalah terkait dengan perilaku berbahasa, khususnya penggunaan bahasa Indonesia. Hal itu sangat penting, agar masyarakat tahu sikap yang diharus diambil jika berhadapan dengan banyaknya bahasa yang ada di masyarakat. Kebermanfaatan dari penilitian ini, adanya kesadaran dari masyarakat untuk selalu mengutamakan Bahasa Indonesia dalam segala bidang. Dengan begitu, Bahasa Indonesia akan menjadi tuan rumah di negaranya sendiri.

\section{METODE}

Jenis penelitian yang digunakan adalah kualitatif deskriptif. Kualitatif deskriptif merupakan penelitian yang melibatkan peneliti sebagai instrumen dalam pengumpulan data. Data yang diambil berasal dari pengalaman peneliti dan informan yang terpercara sehingga peneliti dapat menyimpulkan dan selanjutnya dituangkan dalam konsep poster.

Langkah-langkah penelitian yang dilakukan adalah sebagai berikut: 1) perumusan masalah sikap berbahasa, 2) kajian teori terkait sikap berbahasa dan regulasinya, 3) pengumpulan data melalui narasumber dan lapangan, 4) analisis data (teori, regulasi, narasumber, lapangan), 5) Perancangan poster.

\section{HASIL DAN PEMBAHASAN}

Menurut Anderson (Wagiati, Riyanto, \& Wahya, 2017) sikap bahasa merupakan sebuah keyakinan tentang kebahasaan yang berlangsung relatif lama dan memberikan kecenderungan kepada seseorang untuk bertindak dengan cara tertentu yang disukainya. Anderson membagi sikap atas dua macam, yaitu (1) sikap kebahasaan dan (2) sikap nonkebahasaan. Sikap kebahasaan dapat dikategorikan menjadi dua sikap, yaitu sikap positif dan sikap negatif. Sikap positif 
adalah sikap antusiasme terhadap penggunaan bahasanya. Sebaliknva jika ciri-ciri itu sudah menghilang atau melemah dari diri seseorang atau dari diri sekelompok orang anggota masyarakat, berarti sikap negatif terhadap suatu bahasa telah melanda individua tau kelompok masyarakat tersebut.

Garvin dan Mathiot (Wagiati et al., 2017) merumuskan tiga ciri sikap bahasa, yaitu kesetiaan bahasa (language loyalty), kebanggaan bahasa (language pride), dan kesadaran adanya norma bahasa (awareness of the norm). Sikap bahasa merupakan sikap manusia secara positif atau negatif terhadap bahasa, dialek, logat, dan penutur bahasa yang berlainan.

Sikap bahasa tidak saja ditunjukkan dalam penilaian objektif terhadap ciri-ciri penutur, tetapi juga dalam penilaian objektif terhadap nilai estetika dan betapa standar serta praktikalnya suatu variasi bahasa. Sikap bahasa adalah posisi mental atau perasaan terhadap bahasa sendiri atau bahasa orang lain (Wagiati et al., 2017).

Dari penjelasan beberapa pendapat di atas dapat disimpulkan bahwa sikap berbahasa merupakan keyakinan akan suatu bahasa yang di dalamnya ada kesetiaan, kebangan, dan kesadaran.

Oleh sebab itu, untuk menumbuhkan keyakinan tersebut dan menjalakan keyakinannya, maka diperlukan sebuah usah yang sistematis dan masif.

Usaha sistematis dan masif dilakukan sebagai usaha untuk penguatan posisi bahasa Indonesia atas bahasa yang lain di Indonesia. Hasil dari penelitian ini akan bersifat aplikatif. Masyarakat akan disuguhkan sebuah tuntunan penggunaan bahasa Indonesia yang disampaikan secara digital. Media digital dipilih karena intensitas yang tinggi masyarakat Indonesia atas penggunaan media tersebut. Dengan begitu, penanaman faham atau keyakinan tentang kebahasaan itu akan efektif. Dengan demikian, dimunkinkan akan timbul sikap spontanitas dalam merespon lingkungan terkait masalah kebahasaan, khususnya bahasa Indonesia.

Berikut merupakan ketentuanketentuan sikap bahasa penutur bahasa Indonesia yang nantinya akan dituangkan dalam media poster.

Sikap positif terhadap bahasa Indonesia bagi masyarakat Indonesia mengacu pada Undang-Undang Republik Indonesia Nomor 24 Tahun 2009 tentang Bendera, Bahasa, dan Lambang Negara, serta Lagu Kebangsaan (Presiden Republik Indonesia, 2009). Ketentuan tentang bahasa dalam perundangan tersebut tertuang pada bab III pasal 25 sampai denga pasal 45. Khusus terkait dengan penggunaan bahasa Indonesia tertuang pada pasal 26 sampai dengan pasal 39. Pasal 26 menyebutkan bahwa bahasa Indonesia wajib digunakan dalam perundangan. Selanjutnya, pada pasal 27 disebutkan bahwa bahasa Indonesia digunakan dalam dokumen resmi negara. Pasal 28, bahasa Indonesia wajib digunakan dalam dalam pidato resmi Presiden, Wakil Presiden, dan pejabat negara di dalam atau di luar negeri. Dalam Pendidikan nasional wajib menggunakan bahasa Indonesia sebagai bahasa pengantar. Terkecuali untuk mendukung kemampuan berbahasa asing dan satuan pendidikan asing atau mendidik warga negara asing. Pasal 30 mewajibkan penggunaan bahasa Indonesia untuk pelayanan publik di instansi pemerintah. Bahasa Indonesia juga wajib digunakan dalam nota kesepahaman atau perjanjian lembaga negara, instansi pemerintah, lembaga swasta atau warga negara Indonesia secara perorangan. Dalam nota 
dan perjanjian itu jika melibatkan orang asing, maka ditulis juga dengan bahasa nasional pihak asing tersebut atau bahasa Inggris, sesuai pasal 31. Pada pasal 32, bahasa Indonesia juga wajib digunakan dalam forum yang bersifat nasional atau forum yang bersifat internasional di Indonesia. Ditambah juga bahwa bahasa Indonesia dapat digunakan dalam forum yang bersifat internasional di luar negeri. Bahasa Indonesia wajib digunakan dalam komunikasi resmi di lingkungan kerja pemerintah dan swasta. Bagi pegawai yang ada di Lembaga tersebut belum mahir berbahasa Inonesia, maka wajib diikutsertakan dalam pembelajaran kemampuan berbahasa Indonesia. Hal tersebut tertuang dalam pasal 33. Pasal selanjutnya, 34, diwajibkan penggunaan bahasa Indonesia dalam laporan setiap Lembaga atau perseorangan kepada instansi pemerintah. Pasal 35 juga mewajibkan pengunaan bahasa Indonesia dalam karya ilmiah dan publikasi karya ilmiah di Indonesia. Jika ada bidang kajian khusus dapat menggunakan bahasa daerah atau bahasa asing. Ketentuan pada pasal 36 sangat penting dijadikan perhatian, isinya adalah diwajibkan penggunaan bahasa Indonesia dalam nama geografi di Indonesia yang hanya memiliki satu nama resmi. Diwajibkan juga untuk nama Gedung, jalan, apartemen atau pemukiman, perkantoran, kompleks perdagangan, merek dagang, Lembaga usaha, Lembaga Pendidikan, organisasi, yang didirikan atau dimiliki oleh warga negara atau badan hukum Indonesia. Pengecualian jika ada nilai sejarah, budaya, adat-istiadat, dan/atau keagamaan dapat menggunakan bahasa daerah atau bahasa asing. Pasal 37 juga mewajibkan bahasa Indonesia digunakan dalam informasi tentang produk barang atau jasa produksi dalam negeri atau luar negeri yang beredar di Indonesia dan dapat juga dilengkapi dengan bahasa daerah atau bahasa asing sesuai keperluan. Bahasa Indonesia juga wajib digunakan dalam rambu umum, penunjuk jalan, fasilitas umum, spanduk, dan alat informasi lain untuk pelayanan umum dan dapat juga disertai bahasa daerah dan/atau bahasa asing, pasal 38. Pasal 39 merupakan pasal terakhir terkait kewajiban menggunakan bahasa Indoensia, yaitu dalam informasi melelui media massa dan dapat menggunakan bahasa daerah atau bahasa asing yang mempunyai tujuan khusus atau sasaran khusus (Presiden Republik Indonesia, 2009).

Pada dasarnya dari beberapa ketentuan yang disampaikan di atas lebih banyak kepada penggunaan dan pengutamaan bahasa Indonesia di ruang publik. Menurut prof. Dr. Dadang Sunendar selaku Kepala Badan Pengembangan dan Pembinaan Bahasa ada beberapa tujuan pengutamaan bahasa Indonesia di ruang publik, yaitu (1) memasyaratkan pemakaian bahasa Indonesia, (2) menanamkan sikap positif masyarat terhadap bahasa Indonesia, (3) meningkatkan kesadaran bahwa bahasa Indonesia adalah lambing jati diri bangsa, (4) pemahaman akan penggunaan bahasa Indonesia yang baik dan benar, (5) sebagai bentuk dokumentasi pemakain bahasa di runag publik di wilayah, (6) evaluasi dan pembinaan pemakaian bahasa Indonesia yang baik dan benar di ruang public, dan (7) memartabatkan bahasa Indonesia dengan cara menggunakannya di ruang publik (Badan Pengembangan dan Pembinaan Bahasa, 2016).

\section{PENUTUP}

Simpulan dari penelitian yang telah dilakukan meliputi fakta dari sikap 
berbahasa penutur bahasa Indonesia yang cenderung negatif. Oleh sebab itu, diperlukan sebuah langkah inovatif untuk mengubah perilaku atau sikap berbahasa tersebut. Langkah inovatif yang dilakukan, yaitu dengan melakukan perancangan poster yang berisi tentang kewajiban penggunaan bahasa Indonesia.

Saran untuk penelitian selanjutnya, agar konten terkait penggunaan bahasa Indonesia dapat dikresikan sedemikian rupa yang disesuaikan dengan kedaerahan di Indonesia. Dengan begitu, pembaca tidak merasa asing dengan konten yang disajikan.

\section{REFERENSI}

Badan Pengembangan dan Pembinaan Bahasa. (2016). Pengutamaan Bahasa Indonesia di Ruang Publik. Retrieved January 29, 2019, from http://badanbahasa.kemdikbud.go.id/l amanbahasa/node/2120

Kementerian Komunikasi dan Informatika. (2018). Survei Penggunaan TIK serta Implikasinya terhadap Aspek Sosial Budaya Masyarakat. Retrieved November 24, 2018, from https://kominfo.go.id/index.php/conte $\mathrm{nt} /$ detail/12506/ siaran-pers-

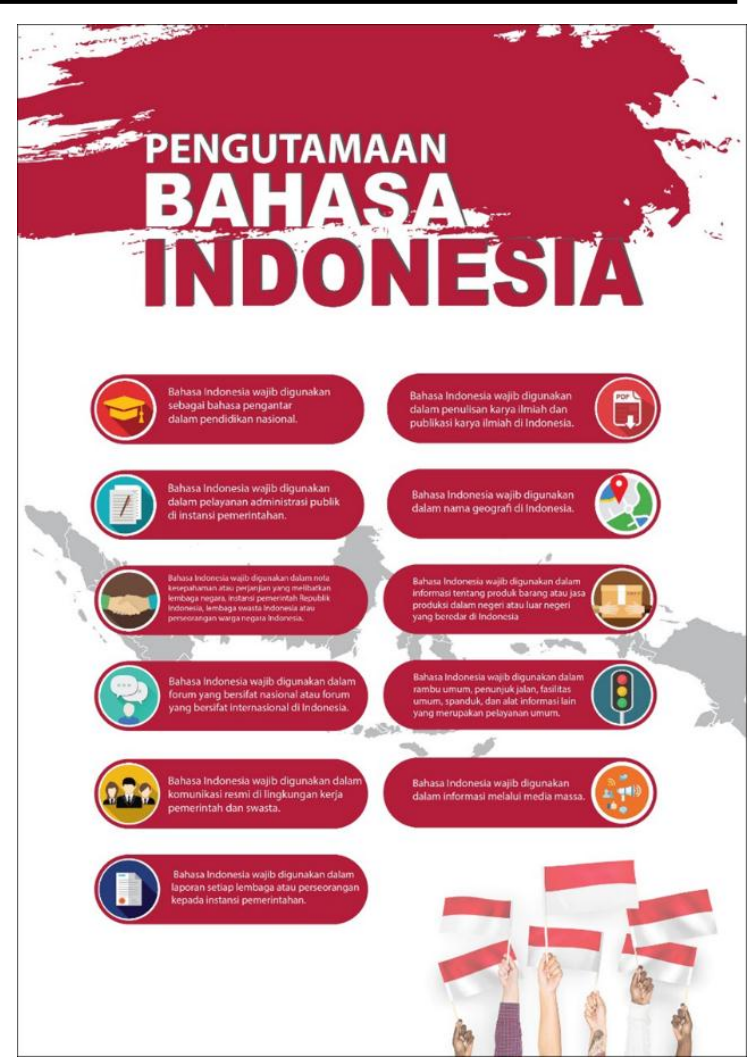

Gambar 3 Poster Pengutamaan Bahasa Indonesia Sumber: Dokumen Pribadi

\section{UCAPAN TERIMA KASIH}

Terima kasih yang setulus-tulusnya penulis sampaikan kepada beberapa pihak yang telah berkontribusi atas penelitian ini, terutama kepada Lembaga Penelitian dan Pengabdian kepada Masyarakat Unindra, Program Studi Desain Komunikasi Visual Unindra, dan Mahasiswa Prodi DKV.

no22hmkominfo012018-tentangsurvei-penggunaan-tik-sertaimplikasinya-terhadap-aspek-sosialbudaya-masyarakat/0/siaran_pers

Presiden Republik Indonesia. (2009). Undang-undang Republik Indonesia No. 24 tahun 2009 tentang bendera, bahasa dan lambang negara, serta lagu kebangsaan. 24/2009. https://doi.org/10.1017/CBO9781107 415324.004

Rizkiansyah, R. A., \& Rustono. (2017). Seloka: Jurnal Pendidikan Bahasa 
dan Sastra Indonesia Perilaku Berbahasa Pengembang Perumahan, Pengelola Hotel, dan Pengelola Toko Abstrak, 6(1), 25-33. Retrieved from https://journal.unnes.ac.id/sju/index.p $\mathrm{hp} /$ seloka/article/view/14750

Wagiati, Riyanto, S., \& Wahya. (2017). Sikap Berbahasa Para Remaja Berbahasa Sunda Di Kabupaten Bandung: Suatu Kajian Sosiolinguistik ( the Language
Attitude of Sundanese-Speaking Teenagers. Metalingua, 15(2), 213221. Retrieved from http://metalingua.kemdikbud.go.id/jur nal/index.php/metalingua/article/view/ 62/72. 